\title{
An overview of the biological and multifunctional roles of IL-38 in different infectious diseases and COVID-19
}

\author{
Pooria Fazeli $^{1} \cdot$ Mohammadreza Saeidnia $^{2} \cdot$ Mehran $_{E^{\prime}}$ Mani $^{3} \cdot$ Mehdi Kalani $^{4}[0$
}

Received: 1 January 2022 / Accepted: 1 March 2022 / Published online: 8 March 2022

(c) The Author(s), under exclusive licence to Springer Science+Business Media, LLC, part of Springer Nature 2022

\begin{abstract}
Undoubtfully, the normal immune system can make a potential response to variable pathogens and neutralize or kill them depending on the type of infection through innate and acquired immunity. Cytokines have poly-peptide nature and are considered as signaling molecules that could amplify or alleviate immune responses besides their other biological functions. Interleukin 38 (IL-38) is a member of the IL-1 family cytokine that, however, its anti-inflammatory role has been observed in different autoimmune diseases like systemic lupus erythematosus (SLE), psoriasis, and Sjogren's syndrome; there is a controversy about the cytokine pro-inflammatory function. In the current review, we skimmed IL-38 structure, signaling mechanism, and its immunological functions, IL-38-producing immune cells. Also, we argued about the role of this cytokine in viral infections including hepatitis B (HBV), hepatitis C (HCV), influenza (Flu), and COVID-19. Also, it illustrated the IL-38 protective effects on sepsis. Moreover, we explained the modulatory role of IL-38 in the COVID-19 cytokine storm.
\end{abstract}

Keywords Interleukin-38 $\cdot$ Infectious diseases $\cdot$ COVID-19 $\cdot$ Cytokine storm

\section{Introduction}

Undoubtfully, the efficient immune system can induce potential responses to different pathogens and can neutralize or kill them based on the type of infectious agent through innate and acquired immunity [1]. Cytokine production is

Mehdi Kalani

mkalani2008@gmail.com

Pooria Fazeli

Pooriafazeli9270@gmail.com

Mohammadreza Saeidnia

m.rezasaeednia@gmail.com

Mehran Erfani

mehranerfani2013@yahoo.com

1 Department of Immunology, School of Medicine, Shiraz University of Medical Sciences, Shiraz, Iran

2 Department of Hematology, School of Paramedical, Shiraz University of Medical Sciences, Shiraz, Iran

3 Department of Biochemistry, School of Medicine, Hormozgan University of Medical Sciences, Bandar Abbas, Iran

4 Department of Immunology, Prof. Alborzi Clinical Microbiology Research Center, Shiraz University of Medical Sciences, Shiraz, Iran recognized as a prominent response induced by specific and nonspecific immune cells. Cytokines with a poly-peptide nature act as signaling molecules that could amplify or alleviate immune responses besides their other biological functions [1, 2]. Interleukin 38 (IL-38) is a new member of the IL-1 family that exhibited anti-inflammatory function in different autoimmune disorders [3, 4], while there is controversy about its pro-inflammatory functions [4, 5]. Regarding the pro- and anti-inflammatory properties of IL-38, studies describing the association between IL-38 and infections are little and its role in infectious diseases is not well understood yet. In the current review, we described the structure, signaling pathways, immunological functions of IL-38, and its role in different infectious diseases, especially in COVID-19 as a newly emerging disease.

\section{IL-38 structure}

Presently, the IL-1 family consisted of 11 members named from IL-1F1 to IL-1F11. IL-1F10 (IL-38) is known as a novel member of the IL-36 subfamily; [6] and its gene locates on chromosome 2q13-14.1 surrounded by IL-1 receptor (IL-1R) and IL-36R genes which act as a receptor antagonist [4]. IL-38 gene is involved in five exons that encode a $17-\mathrm{kDa}$ molecular weight protein without $\mathrm{N}$ - and 
O-linked glycosylation sites and signal peptides $[4,5]$. Like other IL-1 family members, IL-38 needs N-terminal amputation for activation. Nonetheless, a protease that exerts to cut the N-terminal portion of IL-38 still is not determined $[4,5]$. Elaborate studies showed that IL-38 has $7 \mathrm{~h}$ halflife $[3,4]$ and sequence analysis reported that IL-38 shares the highest protein homology with IL-36Ra and IL-1Ra, and lowest homology with IL- $1 \beta$, respectively $[3-5,7]$. After elementary translation, IL-38 found as a soluble form releases two products: a large/major form consisting of 152 amino acids (molecular weight $\sim 25 \mathrm{kDa}$ ), which could be the consequence of posttranslational alterations such as phosphorylation and a small/truncated form consisting of 133 amino acids with 17-kDa molecular weight. Moreover, scientists produced a recombinant form of IL-38 (rIL-38), in vitro $[3-5,7]$, constructed from amino acids 3 to 152 (Fig. 1).

\section{IL-38-producing cells and tissues}

Based on quantitative real-time PCR analysis, IL-38 is expressed in different non-immune organs such as the heart, placenta, and lungs as well as immune organs like the fetal liver, skin, spleen, thymus, and salivary glands $[4,8,9]$. A recent study by Camarillo et al. demonstrated the production of IL-38 in intestinal tissues [10]. Although the highest expression level of IL-38 was detected in the skin and salivary glands $[4,7,8]$ and a basal expression level has been observed in keratinocytes and proliferating B cells [4, $5,7,8,10]$, some factors like inflammatory mediators and bacterial lipopolysaccharide (LPS) can alter this circumstance [5]. Various types of cells for instance cytotoxic $\mathrm{T}$ cells, plasmacytoid dendritic cell (PDC), monocytes, epithelial cells, endothelial cells, parenchymal cell, fibroblastlike synoviocytes, chief cells, parietal cells, and perivascular inflammatory CD123- cells are potent to secret IL-38. Like live cells, Mora et al. found that apoptotic cells could also secrete IL-38 [11]. Among the variations in the level of IL-38, an increased level of IL-38 has been observed in the different autoimmune diseases such as inflammatory bowel disease (IBD), ulcerative colitis [2], rheumatoid arthritis (RA), and psoriasis [4, 8, 10, 12]. Nonetheless, further study must determine other IL-38-producing cells and tissues as well as the levels and roles of IL-38 in different infectious diseases (Fig. 2).

\section{IL-38 signaling pathways}

IL-1R1, IL-36R, and Interleukin 1 Receptor Accessory Protein Like (IL-1RAcP and IL-1RAP-1), which are also called TIGIRR-2 or IL-1R10, are considered the main receptors for IL-38 $[4,7,10]$. There are three distinct scenarios that each noted receptor exerts a special signaling pathway which can determine different properties and roles of IL-38 (Fig. 3).

\section{The first IL-38 signaling pathway}

The first signaling pathway scenario is induced by IL-38/ IL-1R1 axis in which IL- $1 \alpha$ and IL- $1 \beta$ bind to IL-1R1 and consequently activate the corresponding pathway.
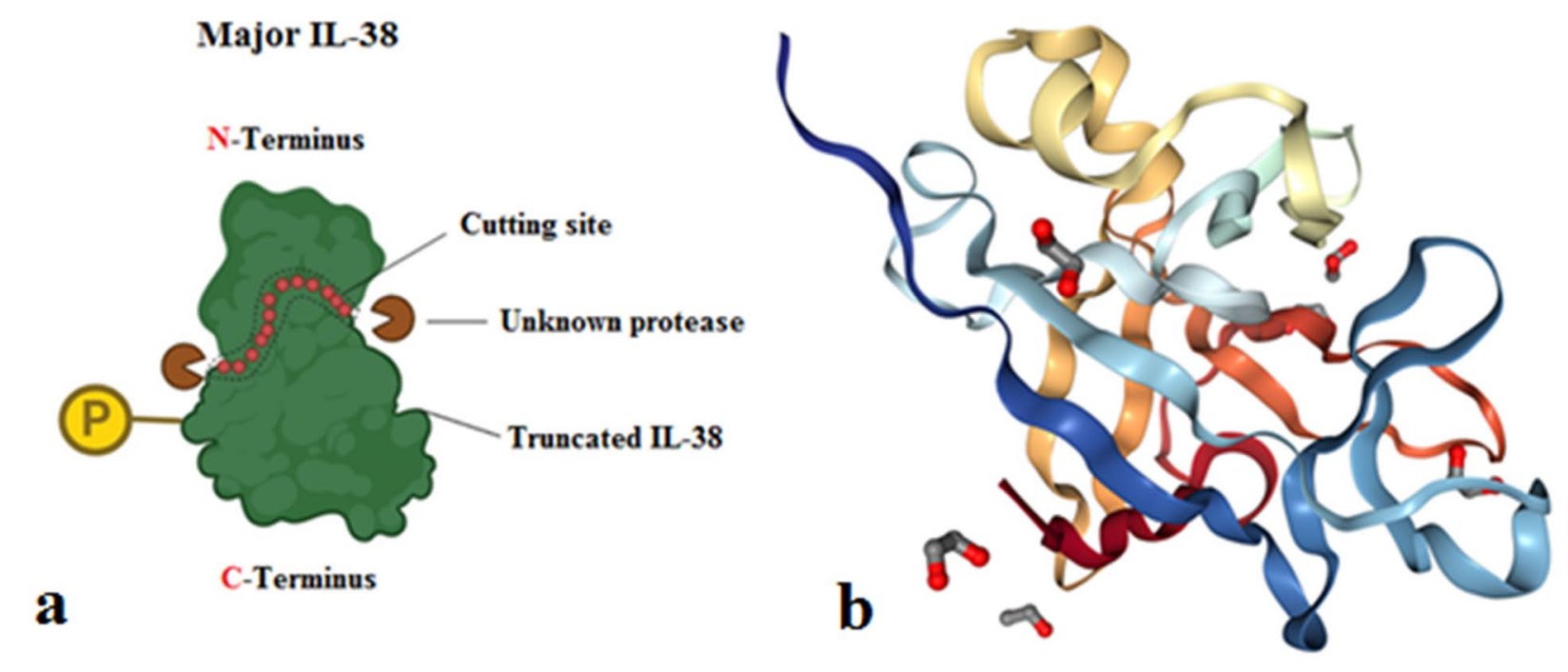

Fig. 1 (a) IL-38 structure. Major IL-38 includes amino acids 1-152 and truncated IL-38 consists of amino acids 20 to 152 . Unknown protease cuts IL-38 N-terminal for its full-activation. (b) Ribbon structure of IL-38 and protein interaction sites 


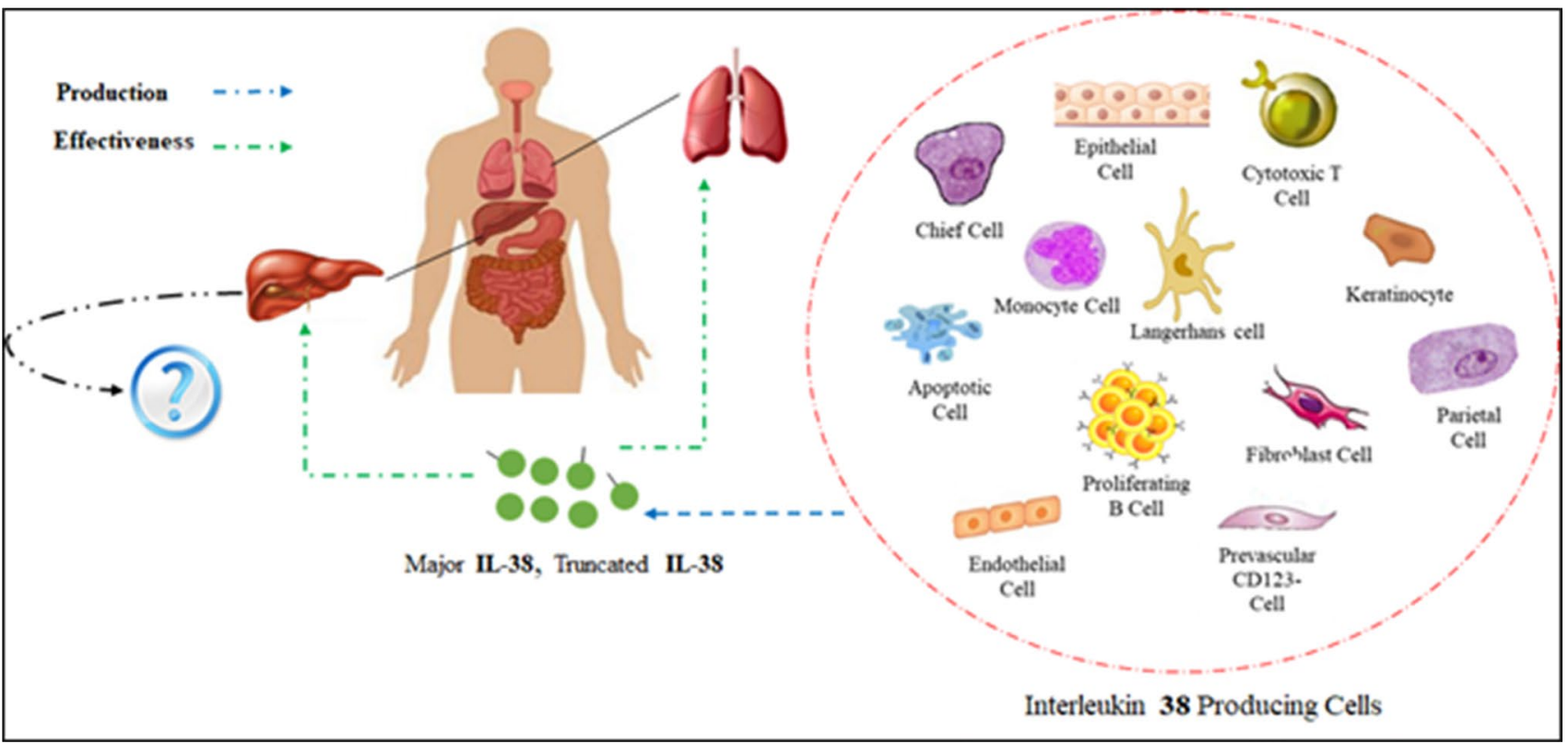

Fig. 2 The effect of IL-38 on the liver- and lung-mediated infectious diseases. Immune and non-immune IL-38-producing cells could modulate the severe inflammation in these organs. Nevertheless, the role of IL-38 in liver infectious diseases such as HBV and HCV is not clear

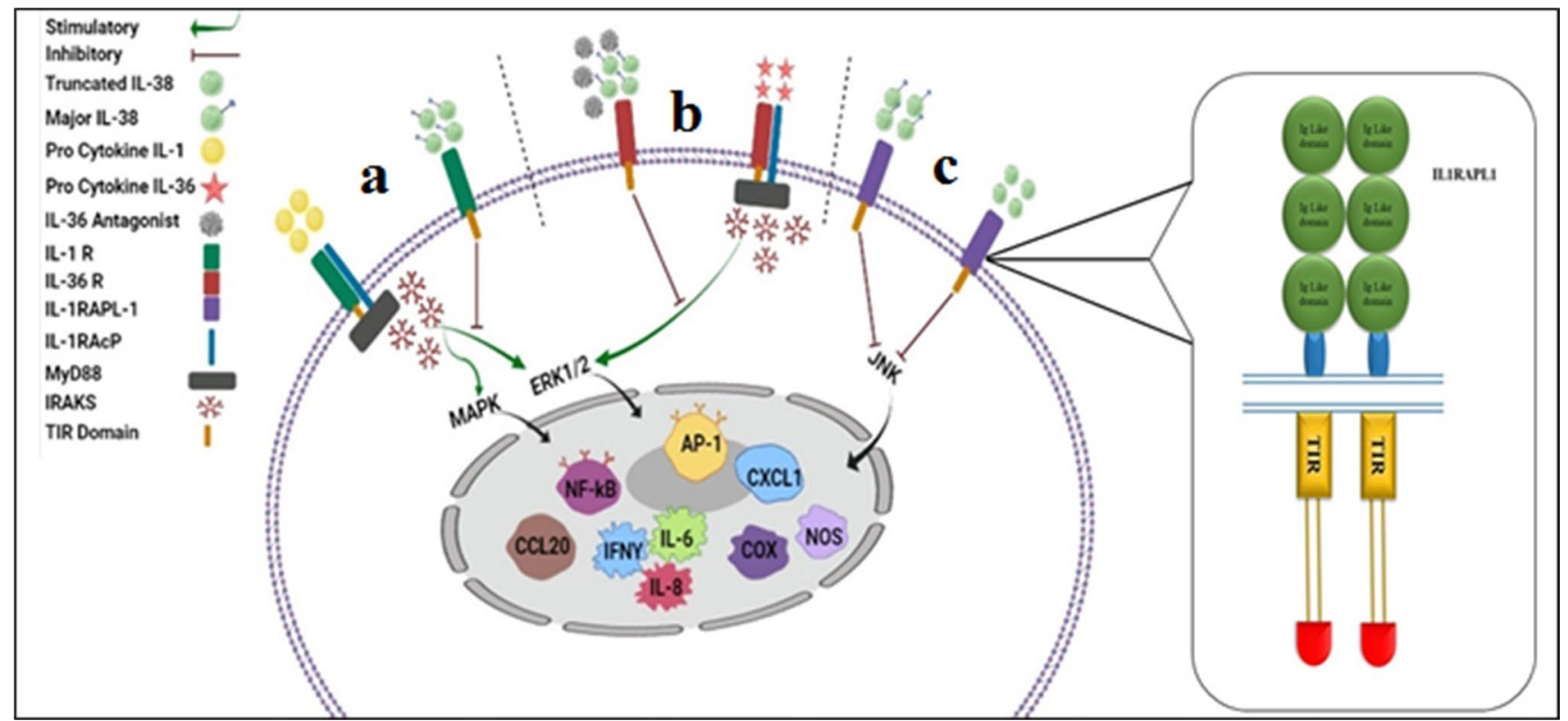

Fig. 3 Different scenarios of IL-38 signaling pathways. (a) Binding of IL-1 pro-cytokines (IL-1 $\alpha$ and IL-1 $\beta$ ) to IL-1R1 employs IL-1RAcP and recruits MyD88 adapter protein. Then, the secretion of IRAKs to switch the pro-inflammatory cascade activates both $\mathrm{NF}-\kappa \mathrm{B}$ and MAPK pathways. Major IL-38 can block these pathways after interaction with IL-1R1. (b) Interaction of IL-36 pro-cytokines (IL-36 $\alpha$, IL-36 $\beta$, and IL-36 $\gamma$ ) with IL-36R activates the pathway like IL-1R1. These responses can be precluded by major IL-38 since it

Interaction between IL-1 pro-cytokines (IL- $1 \alpha$ and $\beta$ ) with heterodimer complex of IL-1R1 and IL-1RAcP or collocated with IL-36R. (c) Both major and truncated forms of IL-38 can bind to IL-1RAPL1 and consequently prohibit the JNK/AP1 pathway. TIR, Toll-Interleukin 1 receptor; MyD88, myeloid differentiation primary response 88 ; IRAKs, interleukin-1 receptor-associated kinases; NF- $\kappa \mathrm{B}$, nuclear factor "kappa-light-chain-enhancer" of activated B-cells; AP-1, activator protein 1. IKK, inhibitory kappa B kinases; MAPK, mitogen-activated protein kinases; JNK, Jun N-terminal kinase

IL-36R results in the recruitment of myeloid differentiation primary response 88 (MyD88) through toll-IL-1 
receptor (TIR) domain that launches the extracellular regulated protein kinases (ERK) 1/2 [8], p38 mitogenactivated protein kinase (MAPK), nuclear factor-kappa $\beta$ (NF- $\kappa \beta$ ) (Fig. 3a), and c-Jun N-terminal kinase (JNK) signal transduction cascade and consequent release of inflammatory cytokines. Contrary to the stimulatory pathway, IL-1Ra acts as an inhibitory factor for IL-1R. This pathway happens through IL-1RAcP dismissing and single immunoglobulin IL-1R-related molecule (SIGIRR) recruitment, which acts as a negative regulator of Toll-interleukin 1 receptor signaling, which can disrupt the inflammatory signals [8, 13, 14]. Regarding the noticeable homology of IL-38 with IL-1Ra, it seems that IL-38 plays an anti-inflammatory role as same as IL1Ra (Fig. 3a). Overall, IL-38/IL-1R axis indicated antiinflammatory properties; however, the role of IL-1R1 in this pathway remains blurred.

\section{The second IL-38 signaling pathway}

The second scenario comprises the interaction between IL-38 and IL-36R (IL-38/IL36R axis). The pro-inflammatory and anti-inflammatory signaling pathway in this axis is similar to IL-38/IL-1R1. Briefly, IL-36 pro-

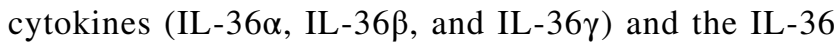
receptor antagonist (IL-36Ra) are considered as the main stimulators and the inhibitor of the IL-36 signaling pathway, respectively $[3-5,13,14]$. The striking point is that nine $\mathrm{N}$-terminal amino acids of the $\mathrm{A}-\mathrm{X}$-Asp conserved motif should be amputated to boost the initiators' activity, extremely. The cytoplasmic TIR domain constitution originates from IL-1RAP-1 employment and reciprocation between IL-36 pro-cytokines and its receptor. The role of the TIR domain is to prepare a binding site for MyD88, which triggers numerous transcription factors such as NF- $\kappa \beta$, MAPK, ERK, JNK, and activator protein 1 (AP1). Finally, IL-36 downstream signaling occurs (Fig. 3b). The outcome of this process upregulates the production of pro-inflammatory cytokines (TNF- $\alpha$, IFN- $\gamma$, and IL-17) [4] as well as cytokines involved in the differentiation and expansion of Th17 such as IL-23 [4]. It is proved that IL-36a represses IL-36R inflammatory responses via concurrent usage of SIGIRR and the blockade of IL-1RAcP recruitment. IL-36R is considered a unique receptor for IL-38. This cytokine has an antagonist effect for IL-36R (Fig. 3b); therefore, it acts similar to IL-36a with the exception of SIGIRR recruitment $[3-5,13,14]$. In addition, IL-38 function is pertinent to its truncated or fulllength form and its concentration [3-5, 7]; nonetheless, more specific receptor study demands to appoint after binding of IL-38 to IL-36R whether the pro-inflammatory effects are to be mitigated or not.

\section{The third IL-38 signaling pathway}

The last scenario is started following the binding of IL-38 with its recently discovered receptors, IL-1RAPL1. IL-1RAPL1 (TIGIRR-2), likewise TIR8 (SIGIRR) and TIGIRR-1 (IL1RAPL2), is an orphan receptor. However, IL-1RAPL1 is a member of the IL-1 receptor cluster; the existence of some differences may distinguish this orphan receptor from the others. Like the other members of the IL-1 receptor family, IL-1RAPL1 consists of three extracellular immunoglobulin (Ig) domains and an intracellular TIR domain, which can trigger the JNK/AP1 pathway. Both forms of IL-38 could link to IL-1RAPL1; however, after binding, they exhibit a contradictory effect $[4,5,7,8,10$, 14] (Fig. 3c).

\section{Multiple biological functions of IL-38}

IL-38 plays various roles depending on its forms (major or truncated), concentration, posttranslational modifications, environmental inducers, and interactions with different receptors $[4,5,7]$. This cytokine is considered as a critical biomarker for immune regulation, tumor survival, and neurobiology [4]. Although most investigations are unanimous about the anti-inflammatory properties of IL-38, its pro-inflammatory effects remain unanswered question.

\section{The anti-inflammatory properties of IL-38}

It is supposed that after binding to IL-36R, low doses of IL36Ra and IL-38 act as anti-inflammatory factors, whereas only their cooperation leads to inflammatory signal transduction $[3,5,7,8,10,13]$. Veerdonk and colleagues reported that in the presence of a low concentration of IL-38 compared with its higher concentration, peripheral blood mononuclear cells (PBMCs) produced a lower level of IL-17 and IL-22 in response to Candida albicans. Also, it reported that activation of the IL38/IL-36R axis could diminish the production of pro-inflammatory cytokine IL-8 from PBMCs. Moreover, IL-38 expression impresses either M1 or M2 macrophage (MQ) activities through decreasing IL-6, TNF$\alpha$, IL-23 produced by M1 macrophages and THP- 1 cells or IL-6 and IL-8 produced by M2 MQs [15]; thereby, IL-38 indirectly participates in the efferocytosis process $[3,7,13$, 16]. Furthermore, it has been reported that in the presence of IL-36Ra, IL-38 amplifies the production of IL-6 by dendritic cells (DCs) stimulated with LPS. It is notable, however, IL-6 is known as a pro-inflammatory cytokine; it could attenuate inflammation in the injured and burned tissues [4, 7, 13]. Additionally, it has been shown that IL-38 induces the expansion of regulatory $\mathrm{T}$ cells and enhances the production of IL-10 by these cells $[3,17]$ that are involved in the modulation of the immune responses. 
On the other hand, albeit some investigations displayed that the small form of IL-38 had a plausible affinity for binding to IL-1R1 somehow could diminish IL-6 secretion by activated macrophages induced by IL- $1 \beta[3,13]$, the same experiments on the major form of IL-38 did not manifest its anti-inflammatory effects [4]. Besides, another finding revealed that IL-38 precludes adverse effects of angiogenesis via decreased levels of human umbilical vein endothelial cell (HUVEC) proliferation and migration [3].

\section{The pro-inflammatory properties of IL-38}

In contrast to its anti-inflammatory, it has been reported that IL-38 is produced in conditions such as apoptosis, necrosis, or inflammation. Although apoptosis is a process to decrease inflammation, necrosis can augment the inflammatory status [16]. A study around tumor biology showed that apoptotic cells assist tumors to survive against macrophage phagocytosis by cytokine secretion [11]. However, data is lacking regarding the pro-inflammatory effects of IL-38 as well as its biological function and it could be a research field for the future study.

Taken together, as shown in Table 1, IL-38 by multifunctional properties and a wide range of effects on target cells and tissues can play pro- and anti-inflammatory roles in the body and act as a pivotal regulator of the immune system. However, further researches are warranted to clarify its exact mechanism and functions in the immune responses.

\section{IL-38 and viral infections}

However, plentiful studies have assessed the role of IL-38 in autoimmune diseases (such as RA, UC, IBD, systemic lupus erythematosus (SLE), psoriasis, and Sjogren's syndrome) [10, 22-24], cancer [11], and cardiovascular diseases [12], and we found limited investigations about the functions of IL-38 in the infectious diseases and especially viral hepatitis induced by hepatitis B and C viruses. Strikingly, IL-38 in viral infections acts as an inflammatory suppressor to regulate the level of inflammation and tissue damage, especially in viral respiratory infections. Regarding the increasing number of COVID-19 patients, its physiopathology similar to the flu and IL-38 double-edged sword function of IL-38 under different inflammatory conditions, we reviewed the role of IL-38 in the mentioned diseases.

\section{IL-38 and HBV}

Based on the type of immune responses to clear HBV infection, the disease may prolong short- or long-term that the patients with chronic HBV are more susceptible to develop hepatocellular carcinoma and liver cirrhosis $[25,26]$. The chronicity of disease may result from the imbalance between the produced $\mathrm{T}$ cell cytokines as well as the potential of HBV to escape from the immune mechanisms [9, 27].

As previously explained, IL-1 clone members are associated with inflammation besides their effects on $\mathrm{T}$ cell population differentiation. Previous investigations have reported that anti-inflammatory members of IL-1 family, such as IL-33 and IL-37, participate in CHB inflammation
Table 1 The effects of IL-38 on the immune and endothelial cells

\begin{tabular}{lllll}
\hline Types of cell & IL-38 effects & Alterations & & Ref \\
\cline { 3 - 4 } & & Ascending & Descending & \\
\hline PBMCs & IL-8 production & & $\checkmark$ & {$[13]$} \\
TH1 cells & IL-1 $\beta$, TNF- $\alpha$, and IFN- $\gamma$ production & & $\checkmark$ & {$[13]$} \\
TH17 cells & IL-6, IL-17, and IL-22 production & & $\checkmark$ & {$[13]$} \\
$\gamma \delta$ T cells & IL-17 production & & & {$[13,18]$} \\
T reg cells & Frequency & $\checkmark$ & & {$[17,19]$} \\
& IL-10 production & $\checkmark$ & $\checkmark$ & {$[17,19]$} \\
M1 cells & TNF- $\alpha$, IL-6, and IL-23 production & & $\checkmark$ & {$[13,18]$} \\
M2 cells & IL-6 \& IL-8 production (assist to effero- & & $\checkmark$ & {$[13,20]$} \\
THP1 cells & cytosis process) & & & {$[13]$} \\
DCs & TNF- $\alpha$, IL-6, and IL-23 production & & $\checkmark$ & {$[21]$} \\
HUVECs & IL-6 production & & $\checkmark$ & \\
\hline
\end{tabular}

PBMC peripheral blood mononuclear cell, TH1 T helper $1, T H 17$ T helper $17, T$ reg regulatory T cell, $M 1$ macrophage type 1, M2 macrophage type 2, DC dendritic cell, $H U V E C$ human umbilical vein endothelial cell, THP 1 human monocytic cell line derived from an acute monocytic leukemia patient 
and consequently can cause liver damage. IL-38 as another member of the IL-1 cluster manifested anti-inflammatory features that are insignificantly argued about its role in CHB inflammation. In 2015, Wang et al. reported the serum level of IL-38 was significantly higher in CHB patients than that in the normal controls $(P=0.01)$; in addition, IL-38 serum level had a noticeable direct correlation with aspartate aminotransferase (AST) levels in patients with CHB. After treatment by nucleoside analog like telbivudine (LdT), the IL-38 serum-level comes back to the basal level. Also, the upregulated IL-38 was associated with a more possibility of virological response (VR) to LdT treatment at 24 weeks. They suggested that IL-38 act as an indicator of liver-damaging, based on a positive correlation with AST. Moreover, it is possible that upregulated IL-38 results from hepatic necroinflammation reflecting viral resolution through infected hepatocyte destroying. So, it could justify the direct correlation between IL-38 serum level and the possibility of VR during treatment by LdT [9]. In contrast to the study by Wang et al.and Shakir et al., it has been demonstrated that IL-38 serum level was lower in CHB patients than healthy control and they assumed a high level of this cytokine could be pathogenic in HBV circumstances [28]. Overall, it is obvious that IL-38 play important roles in HBV infection responses and its fruitful or detrimental effects depend on the disease stages, IL-38 concentration [4], form, and signaling pathways. Thereby, more detailed investigations are demanded to clarify its effectiveness.

\section{IL-38 and HCV}

The majority of HCV infection challenge accounts for approximately $3 \%$ worldwide. It may progress to chronic infection in about $80 \%$ of HCV-infected individuals [29-31]. However, interferon types I and III are the main actors in HCV infection resolution; the IL-1 family also play a role. For instance, several studies have proved that IL- $1 \beta$ and IL-18 serum levels increase in HCV patients. Like HBV, simultaneously elevated serum levels of IL-33 and IL-18 in $\mathrm{HCV}$ patients could lead to a specific immune cell recruitment for potentiating the viral clearance $[32,33]$. However, the role of IL-38 as a member of the IL-1 family in HCV disease is still undefined. Our recent study revealed the effect of IL-38 on HCV disease (unpublished data). We observed that the serum levels of IL-38 were lower in HCV pretreatment patients rather than post-treatment patients as well as healthy controls $(P<0.014$ and $P<0.0001$, respectively). In addition, there was a negative correlation between IL-38 serum level and alkaline phosphatase (ALP). This study suggested that the decreased level of IL-38 in untreated patients is the consequence of immense amounts of inflammatory cytokines presence. Moreover, similar to HBV, the phase of the disease, the type of intervention (Sofosbuvir and Daclatasvir), and IL-38 properties can impact its function. Nonetheless, further studies must determine the role of IL-38 in HCV disease.

\section{IL-38 and influenza viruses}

Human influenza virus infections have a worldwide distribution [34]. In terms of pathogenicity, influenza viruses in human causes a broad spectrum of clinical disease manifestations ranging from asymptomatic infection to death [35]. Pathological studies showed that an imbalanced host immune response to viral pathogenicity contributed to fatal lung injury in respiratory viral infection, characterized by high viral load, excessive cytokine expression, and overwhelming immune cell influx [36]. These dysfunctional immune responses are often associated with fatal outcomes during respiratory viral infection, and downregulation of excessive immune response is crucial in minimizing severe immunopathology. Many studies are developing in an attempt to mitigate viral-related lung injury through targeting pro-inflammatory molecules. Among them, IL-38, a novel anti-inflammatory cytokine with suppressive properties, exerts immunomodulatory roles in respiratory viral infections [37]. A study showed that IL-38 expression was extendedly upregulated in response to different kinds of respiratory viral infections to suppress the induced inflammation. Demonstrated for the first time, the clinical relevance of IL-38 expression in patients with influenza virus and SARSCoV-2 infection suggests the predictive role of IL-38 in the prognosis of respiratory viral infection [37]. Therefore, a detailed understanding of the factors that regulate the balance between viral clearance, tissue damages, and resolution of inflammation is necessary for the identification.

\section{IL-38 and COVID-19}

In late 2019, severe acute respiratory syndrome coronavirus 2 (SARS-CoV-2) emerged as the new species of virulent agent and become eventually pandemic around the world. Based on the involvement of the lungs and the induction of severe acute respiratory syndrome, the induced disease was named coronavirus disease (COVID)-19 by the World Health Organization (WHO) $[38,39]$. Inflammatory cytokine storm or secondary bacterial infections are known as the main causes of severe disease complications and even patient fatality $[35,38,40]$. Clinical studies showed that the SARSCov-2 triggers extensive inflammatory responses through linking to TLR that switches on IL-1 secretion, the prime cause of fever and fibrosis. The monocytes are the principal source of pro-inflammatory cytokines and chemokines such as IL-1 $\beta$, IL-2, IL-4, IL-5, IL-6, IL-7, IL-8, IP-10, IL-12, IL-13, IL-17, TNF- $\alpha$, CCL-2, CCL-5, and CXCL10. It is supposed that the high levels of cytokines IL-1 $\beta$, 
IL-7, and IL-8 can aggravate lung involvement $[35,37,38$, 40, 41]. Apart from drug interventions like antiviral and antibacterial agents, novel therapy exerts anti-inflammatory cytokines in which IL-38 with immunomodulatory properties may become critical [39]. Although we previously described immensely the immunomodulatory roles of IL-38, Gao et al. investigated precisely animal models and observed that IL-38 can control respiratory inflammation and cytokine storm mediated by protective mechanisms. They found that circulating IL-38 levels with IL-36 $\alpha$ raised meaningfully in COVID-19 patients rather than healthy individuals [37]. Gao and colleagues reported in the mice model of poly (I:C) that in induced lung inflammation, IL-38 increased the frequency of $\mathrm{CD}^{+}{ }^{+} \mathrm{CD} 25^{+} \mathrm{FOXP}^{+}$splenic $\mathrm{T}$ reg cells in the lung. Furthermore, IL-38 declined the proportion of IL-17-producing $\mathrm{T} \gamma \delta$ cells and reduced neutrophils that are known as the source of IL- $1 \beta$, TNF- $\alpha$, and IL- 6 . Table 2 demonstrates IL-38 immune-regulatory effects and its consequences for improving respiratory inflammation during SARS-CoV-2 infection in an animal study [39].

\section{IL-38 and bacterial infection}

There are limited studies in the world on the function of IL-38 in bacterial infections. The most important of which is the association of interleukin-38 with sepsis.

\section{IL-38 and sepsis}

Sepsis is known as life-threatening acute organ dysfunction $[42,43]$. Although bacterial infections are defined as the most in-vogue cause of the disease, viral, fungal, and parasite infections are also introduced as possible causative agents [44]. Sepsis is correlated with significant morbidity and mortality and its signs manifest as fast heart rate, quick or short breathing, fever, chill, and mental disorientation $[43,44]$. The disease leads to immune system imbalance and releases continuously huge number of pro-inflammatory cytokines including IL-1, IL-6, and TNF- $\alpha$ [42, 45, 46]. Several studies showed anti-inflammatory cytokines are effective for inflammatory response contraction $[18,39$, 47]. We found two studies that investigated the protective role of IL-38 in lipopolysaccharide (LPS)-challenged mice, cecal ligation and puncture (CLP)-induced sepsis models, and human volunteers. Ge et al. observed not only IL-38/IL-36R axis was overexpressed in murine $\mathrm{CD} 4+\mathrm{CD} 25+\mathrm{T}$ reg cells, but also its secretion was enhanced after LPS stimulation (49). Moreover, IL-38 induced upregulation of forkhead box P3 (FOXP3) gene and cytotoxic T-lymphocyte-associated protein 4 (CTLA-4) in CD4 + CD25 + T reg cells. They reported that the treatment of $\mathrm{CD} 4+\mathrm{CD} 25+\mathrm{T}$ reg cells with IL-38 enhanced the production of anti-inflammatory cytokines (IL-10 and TGF- $\beta 1$ ) and potential lymphoproliferation suppression compared with untreated ones. Also, they found that IL-38 as a therapeutic factor can reduce CLPinduced death when administered at the early phase of the disease [48]. In another study, Xu and colleagues reported that serum IL-38 levels had a noticeable rising in adult and pediatric patients with sepsis compared with corresponding healthy controls. Furthermore, it reduced inflammatory responses through dwindling IL-6, TNF- $\alpha$, IL-10, IL-17, IL-27, CXCL1, and CCL2, which could result in lessening tissue injury in CLP-induced sepsis. Besides, bacterial clearance in CLP-induced polymicrobial sepsis was an invaluable anti-inflammatory effect of IL-38. Therefore, IL-38 can play a modulatory role in the immunopathogenesis of sepsis and it could be exerted as antisepsis therapy along with IL-5, IL-7, IL-30, IL-33, and progranulin [49].

\section{Conclusion}

Although it is suggested that IL-38 play anti-inflammatory roles in HBV, HCV, influenza, and COVID-19 infections, controversy is around its function in HBV infection. Furthermore, in patients with severe COVID-19, the overexpressed IL-38 can confer its function in the immunopathogenesis of COVID-19 and it could be considered a predictive factor for the prognosis of induced respiratory inflammation. Given the limited studies exploring the functions of IL-38 in bacterial infections such as its anti-inflammatory properties in translational models of sepsis, further studies are recommended to clarify its role in other bacterial life-threatening

Table 2 IL-38 protective effects and its consequence in mice poly(I:C) induced lung inflammation [39]

\begin{tabular}{|c|c|c|}
\hline Target & The effects & Consequence \\
\hline $\begin{array}{l}\text { CD } 4+\text { CD } 25+\text { Foxp } 3+\text { splenic Treg } \\
\text { cells }\end{array}$ & Upregulation & $\begin{array}{l}\text { Improving severe acute lung injury } \\
\text { Rising blood oxygen level }\end{array}$ \\
\hline Myeloid and lymphoid cells & $\begin{array}{l}\text { Mitigate their numbers and the production of IL-17, CXCL-1, } \\
\text { CXCL-10, CCL-2, and CCL-5 }\end{array}$ & Improving lung inflammation \\
\hline Neutrophils & $\begin{array}{l}\text { Reduce their number leading to downregulation of IL- } 1 \beta \text {, TNF- } \alpha \text {, } \\
\text { and IL- } 6\end{array}$ & Alleviate cytokine storm \\
\hline
\end{tabular}


diseases such as pneumonia and meningitis. Nevertheless, it is remained obscure to determine the role of IL-38 in other infections induced by the parasite and fungal agents. To determine the exact mechanisms, optimal doses, different forms, and signaling pathways involved in bacterial, fungal, and parasite infections, further study is warranted.

\section{Declarations}

Conflict of interest The authors declare no competing interests.

\section{References}

1. Nicholson LB. The immune system. Essays Biochem. 2016;60(3):275-301. https://doi.org/10.1042/EBC20160017.

2. Costela-Ruiz VJ, Illescas-Montes R, Puerta-Puerta JM, Ruiz C, Melguizo-Rodríguez L. SARS-CoV-2 infection: The role of cytokines in COVID-19 disease. Cytokine Growth Factor Rev. 2020;54:62-75. https://doi.org/10.1016/j.cytogfr.2020.06.001.

3. Xu WD, Huang AF. Role of Interleukin-38 in Chronic Inflammatory Diseases: A Comprehensive Review. Front Immunol. 2018;9:1462. https://doi.org/10.3389/fimmu.2018.01462.

4. Xie L, Huang Z, Li H, Liu X, Zheng S, Su W. IL-38: A New Player in Inflammatory Autoimmune Disorders. Biomolecules. 2019;9(8):345. https://doi.org/10.3390/biom9080345.

5. Xia HS, Liu Y, Fu Y, Li M, Wu YQ. Biology of interleukin-38 and its role in chronic inflammatory diseases. Int Immunopharmacol. 2021. https://doi.org/10.1016/j.intimp.2021.107528

6. Boutet MA, Nerviani A, Pitzalis C. IL-36, IL-37, and IL-38 Cytokines in Skin and Joint Inflammation: A Comprehensive Review of Their Therapeutic Potential. Int J Mol Sci. 2019;20(6):1257. https://doi.org/10.3390/ijms20061257.

7. Yuan X, Peng X, Li Y, Li M. Role of IL-38 and its related cytokines in inflammation. Mediators Inflamm. 2015;2015:807976. https:// doi.org/10.1155/2015/807976.

8. Boutet MA, Bart G, Penhoat M, Amiaud J, Brulin B, Charrier C, Morel F, Lecron JC, Rolli-Derkinderen M, Bourreille A, Vigne S, Gabay C, Palmer G, Le Goff B, Blanchard F. Distinct expression of interleukin (IL)-36 $\alpha, \beta$ and $\gamma$, their antagonist IL-36Ra and IL-38 in psoriasis, rheumatoid arthritis and Crohn's disease. Clin Exp Immunol. 2016;184(2):159-73. https://doi.org/10.1111/cei. 12761.

9. Wang HJ, Jiang YF, Wang XR, Zhang ML, Gao PJ. Elevated serum interleukin-38 level at baseline predicts virological response in telbivudine-treated patients with chronic hepatitis B. World J Gastroenterol. 201614;22(18):4529-37. https://doi.org/ 10.3748/wjg.v22.i18.4529.

10. Fonseca-Camarillo G, Furuzawa-Carballeda J, Iturriaga-Goyon E, Yamamoto-Furusho JK. Differential Expression of IL-36 Family Members and IL-38 by Immune and Nonimmune Cells in Patients with Active Inflammatory Bowel Disease. Biomed Res Int. 2018;2018:5140691. https://doi.org/10.1155/2018/5140691.

11. Mora J, Schlemmer A, Wittig I, Richter F, Putyrski M, Frank AC, Han Y, Jung M, Ernst A, Weigert A, Brüne B. Interleukin-38 is released from apoptotic cells to limit inflammatory macrophage responses. J Mol Cell Biol. 2016;8(5):426-38. https://doi.org/10. 1093/jmcb/mjw006.

12. de Graaf DM, Jaeger M, van den Munckhof ICL, Ter Horst R, Schraa K, Zwaag J, Kox M, Fujita M, Yamauchi T, Mercurio L,
Madonna S, Rutten JHW, de Graaf J, Riksen NP, van de Veerdonk FL, Netea MG, Joosten LAB, Dinarello CA. Reduced concentrations of the $\mathrm{B}$ cell cytokine interleukin 38 are associated with cardiovascular disease risk in overweight subjects. Eur J Immunol. 2021;51(3):662-71. https://doi.org/10.1002/eji.201948390.

13. van de Veerdonk FL, Stoeckman AK, Wu G, Boeckermann AN, Azam T, Netea MG, Joosten LA, van der Meer JW, Hao R, Kalabokis V, Dinarello CA. IL-38 binds to the IL-36 receptor and has biological effects on immune cells similar to IL-36 receptor antagonist. Proc Natl Acad Sci U S A. 2012;109(8):3001-5. https://doi.org/10.1073/pnas.1121534109.

14. Palomo J, Dietrich D, Martin P, Palmer G, Gabay C. The interleukin (IL)-1 cytokine family-Balance between agonists and antagonists in inflammatory diseases. Cytokine. 2015;76(1):25-37. https://doi.org/10.1016/j.cyto.2015.06.017.

15. Atri C, Guerfali FZ, Laouini D. Role of Human Macrophage Polarization in Inflammation during Infectious Diseases. Int $\mathbf{J}$ Mol Sci. 2018;19(6):1801. https://doi.org/10.3390/ijms19061801.

16. Garraud T, Harel M, Boutet MA, Le Goff B, Blanchard F. The enigmatic role of IL-38 in inflammatory diseases. Cytokine Growth Factor Rev. 2018;39:26-35. https://doi.org/10.1016/j. cytogfr.2018.01.001.

17. Chu M, Chu IM, Yung EC, Lam CW, Leung TF, Wong GW, Wong CK. Aberrant Expression of Novel Cytokine IL-38 and Regulatory T Lymphocytes in Childhood Asthma. Molecules. 2016;21(7):933. https://doi.org/10.3390/molecules21070933.

18. Boutet MA, Najm A, Bart G, Brion R, Touchais S, Trichet V, Layrolle P, Gabay C, Palmer G, Blanchard F, Le Goff B. IL-38 overexpression induces anti-inflammatory effects in mice arthritis models and in human macrophages in vitro. Ann Rheum Dis. 2017;76(7):1304-12. https://doi.org/10.1136/annrh eumdis-2016-210630.

19. Chu M, Tam LS, Zhu J, Jiao D, Liu H, Cai Z, Dong J, Kai Lam CW, Wong CK. In vivo anti-inflammatory activities of novel cytokine IL-38 in Murphy Roths Large (MRL)/lpr mice. Immunobiology. 2017;222(3):483-93. https://doi.org/10.1016/j. imbio.2016.10.012.

20. Yuan XL, Li Y, Pan XH, Zhou M, Gao QY, Li MC. [Production of recombinant human interleukin-38 and its inhibitory effect on the expression of proinflammatory cytokines in THP-1 cells]. Mol Biol (Mosk). 2016;50(3):466-73. Russian. https://doi.org/ $10.7868 / \mathrm{S} 0026898416030137$.

21. Zhang J, Zhao R, Chen J, Jin J, Yu Y, Tian Y, Li W, Wang W, Zhou H, Bo SuS. The Effect of Interleukin 38 on Angiogenesis in a Model of Oxygen-induced Retinopathy. Sci Rep. 2017;7(1):2756. https://doi.org/10.1038/s41598-017-03079-z.

22. Xu WD, Su LC, He CS, Huang AF. Plasma interleukin-38 in patients with rheumatoid arthritis. Int Immunopharmacol. 2018;65:1-7. https://doi.org/10.1016/j.intimp.2018.09.028.

23. Xu WD, Su LC, Liu XY, Wang JM, Yuan ZC, Qin Z, Zhou XP, Huang AF. IL-38: A novel cytokine in systemic lupus erythematosus pathogenesis. J Cell Mol Med. 2020;24(21):12379-89. https://doi.org/10.1111/jcmm.15737.

24. Luo D, Chen Y, Zhou N, Li T, Wang H. Blockade of Th17 response by IL-38 in primary Sjögren's syndrome. Mol Immunol. 2020;127:107-11. https://doi.org/10.1016/j.molimm.2020. 09.006.

25. Gunson RN, Shouval D, Roggendorf M, Zaaijer H, Nicholas H, Holzmann H, de Schryver A, Reynders D, Connell J, Gerlich WH, Marinho RT, Tsantoulas D, Rigopoulou E, Rosenheim M, Valla D, Puro V, Struwe J, Tedder R, Aitken C, Alter M, Schalm SW, Carman WF; European Consensus Group. Hepatitis $\mathrm{B}$ virus (HBV) and hepatitis $\mathrm{C}$ virus (HCV) infections in health care workers (HCWs): guidelines for prevention of transmission of $\mathrm{HBV}$ and $\mathrm{HCV}$ from HCW to patients. J Clin Virol. 
2003;27(3):213-30. https://doi.org/10.1016/s1386-6532(03) 00087-8.

26. Liaw YF, Chu CM. Hepatitis B virus infection. Lancet. 2009;373(9663):582-92. https://doi.org/10.1016/S01406736(09)60207-5.

27. Jung MC, Pape GR. Immunology of hepatitis B infection. Lancet Infect Dis. 2002;2(1):43-50. https://doi.org/10.1016/s14733099(01)00172-4.

28. Alaaraji SF. Exploration of the Relationship between Interleukins 17, 37 and 38 with Vitamin E in Iraqi Men with CHB. InJournal of Physics: Conference Series 2019 Sep 1 (Vol. 1294, No. 5, p. 052047). Bristol: IOP Publishing.

29. van der Meer AJ, Veldt BJ, Feld JJ, Wedemeyer H, Dufour JF, Lammert F, Duarte-Rojo A, Heathcote EJ, Manns MP, Kuske L, Zeuzem S, Hofmann WP, de Knegt RJ, Hansen BE, Janssen HL. Association between sustained virological response and all-cause mortality among patients with chronic hepatitis $\mathrm{C}$ and advanced hepatic fibrosis. JAMA. 2012;308(24):2584-93. https://doi.org/10.1001/jama.2012.144878.

30. Li H, Huang MH, Jiang JD, Peng ZG. Hepatitis C: From inflammatory pathogenesis to anti-inflammatory/hepatoprotective therapy. World J Gastroenterol. 2018;24(47):5297-311. https://doi. org/10.3748/wjg.v24.i47.5297.

31. Park SH, Rehermann B. Immune responses to HCV and other hepatitis viruses. Immunity. 2014;40(1):13-24. https://doi.org/10. 1016/j.immuni.2013.12.010.

32. Tsutsui H, Cai X, Hayashi S. Interleukin-1 Family Cytokines in Liver Diseases. Mediators Inflamm. 2015;2015:630265. https:// doi.org/10.1155/2015/630265

33. Barbier L, Ferhat M, Salamé E, Robin A, Herbelin A, Gombert JM, Silvain C, Barbarin A. Interleukin-1 Family Cytokines: Keystones in Liver Inflammatory Diseases. Front Immunol. 2019;10:2014. https://doi.org/10.3389/fimmu.2019.02014.

34. Fauci AS. Seasonal and pandemic influenza preparedness: science and countermeasures. J Infect Dis. 2006;194(Suppl 2):S73-6. https://doi.org/10.1086/507550.

35. Flerlage T, Boyd DF, Meliopoulos V, Thomas PG, SchultzCherry S. Influenza virus and SARS-CoV-2: pathogenesis and host responses in the respiratory tract. Nat Rev Microbiol. 2021;19(7):425-41. https://doi.org/10.1038/s41579-021-00542-7.

36. McNab F, Mayer-Barber K, Sher A, Wack A, O'Garra A. Type I interferons in infectious disease. Nat Rev Immunol. 2015;15(2):87-103. https://doi.org/10.1038/nri3787.

37. Gao X, Chan PKS, Lui GCY, Hui DSC, Chu IM, Sun X, Tsang MS, Chan BCL, Lam CW, Wong CK. Interleukin-38 ameliorates poly(I:C) induced lung inflammation: therapeutic implications in respiratory viral infections. Cell Death Dis. 2021;12(1):53. https:// doi.org/10.1038/s41419-020-03283-2.
38. Lin SH, Zhao YS, Zhou DX, Zhou FC, Xu F. Coronavirus disease 2019 (COVID-19): cytokine storms, hyper-inflammatory phenotypes, and acute respiratory distress syndrome. Genes Dis. 2020;7(4):520-7. https://doi.org/10.1016/j.gendis.2020.06.009.

39. Salvi R, Patankar P. Emerging pharmacotherapies for COVID19. Biomed Pharmacother. 2020. https://doi.org/10.1016/j.biopha. 2020.110267.

40. Yalcin AD, Yalcin AN. Future perspective: biologic agents in patients with severe COVID-19. Immunopharmacol Immunotoxicol. 2021;43(1):1-7. https://doi.org/10.1080/08923973.2020. 1818770.

41. Conti P, Ronconi G, Caraffa A, Gallenga CE, Ross R, Frydas I, et al. Induction of pro-inflammatory cytokines (IL-1 and IL-6) and lung inflammation by Coronavirus-19 (COVI-19 or SARSCoV-2): anti-inflammatory strategies. J Biol Regul Homeost Agents. 2020;34(2):327-31. https://doi.org/10.23812/conti-e.

42. Prescott HC, Angus DC. Enhancing Recovery From Sepsis: A Review. JAMA. 2018 Jan 2;319(1):62-75. doi: 10.1001/ jama.2017.17687.

43. Cecconi M, Evans L, Levy M, Rhodes A. Sepsis and septic shock. Lancet. 2018;392(10141):75-87. https://doi.org/10.1016/S01406736(18)30696-2.

44. Angus DC, van der Poll T. Severe sepsis and septic shock. N Engl J Med. 2013;369(9):840-51. https://doi.org/10.1056/NEJMra1208 623.

45. Lee WLJA. Immunotherapy for sepsis: a good idea or another dead end? Anesthesiology 2018;129(1):5-7.

46. Hotchkiss RS, Monneret G, Payen DJNRI. Sepsis-induced immunosuppression: from cellular dysfunctions to immunotherapy. 2013;13(12):862-74.

47. Peters van Ton AM, Kox M, Abdo WF, Pickkers P. Precision immunotherapy for sepsis. Front Immunol. 2018;9:1926. https:// doi.org/10.3389/fimmu.2018.01926.

48. Ge Y, Huang M, Wu Y, Dong N, Yao YM. Interleukin-38 protects against sepsis by augmenting immunosuppressive activity of CD4+ CD25+ regulatory T cells. J Cell Mol Med. 2020;24(2):2027-39. https://doi.org/10.1111/jcmm.14902.

49. $\mathrm{Xu} \mathrm{F,} \mathrm{Lin} \mathrm{S,} \mathrm{Yan} \mathrm{X,} \mathrm{Wang} \mathrm{C,} \mathrm{Tu} \mathrm{H,} \mathrm{Yin} \mathrm{Y,} \mathrm{Cao} \mathrm{J.} \mathrm{Interleukin} 38$ Protects Against Lethal Sepsis. J Infect Dis. 2018;218(7):117584. https://doi.org/10.1093/infdis/jiy289.

Publisher's note Springer Nature remains neutral with regard to jurisdictional claims in published maps and institutional affiliations. 